\title{
Concept Design of a Tram Bogie with Atypical Suspension
}

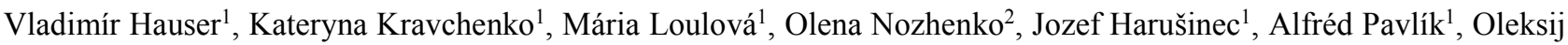 \\ Fomin $^{3}$ \\ ${ }^{1}$ University of Zilina, Faculty of Mechanical Engineering, Department of Transport and Handling Machines. Univerzitna \\ 1, 01026 Zilina, Slovak Republic. E-mail: vladimir.hauser@fstroj.uniza.sk, kateryna.kravchenko@fstroj.uniza.sk, ma- \\ ria.loulova@fstroj.uniza.sk, jozef.harusinec@fstroj.uniza.sk, alfred.pavlik@fstroj.uniza.sk \\ ${ }^{2}$ Volodymyr Dahl East Ukrainian National University. Tscentralny av. 59a, 93400 Severodonetsk, Ukraine. E-mail: noz- \\ henko.olena@gmail.com \\ ${ }^{3}$ State University of Infrastructure and Technology, Department of cars and carriage facilities. Kyrylivska str. 9, 04071 \\ Kiev, Ukraine. E-mail: fomin1985@ukr.net
}

In the urban railways environment, there is considerable stress of the track due to operation, which results in extensive deformation of the track geometric position, wear of the rail heads, expansion of the free channel of the track, leading to an increase in steering forces in the rail-wheel contact and further worsening of the situation. The authors perceive this situation primarily as a consequence of an inappropriate bogie concept of the operating vehicles - not of the track quality. The article focuses on designing a new bogie concept that takes into account the specific environmental conditions for which it is intended. The presented bogie design is characterized by the mounting of the frame on the wheelsets by means of three bearing boxes and the presence of a mechanism for adjusting the radial position of the wheelsets during ride in track arcs. This is a new, unconventional solution for which a number of patent applications have been filed. Simulation analyzes of vehicle ride with the designed bogie are currently underway. On the basis of the first results, it is foreseen that the design will increase the life of the track several times, reduce the energy consumption of vehicles and the environmental load of the environment through the transport system.

Keywords: track-friendly bogie, wheel load deviation, tram bogie concept, wheelset positioning in track curve

\section{Introduction}

The bogie represents an important part of a rail vehicle, which significantly affects its driving characteristics, it affects the running costs not only of the vehicle itself but also of its transport route. In designing the bogie concept, it is therefore necessary to respect the specificics of the environment in which it will be operated. Various rail defects can be observed on our as well as on European routes. In the classical railway environment, due attention is given to the rail condition, deviations from the required operating values are continuously eliminated. However, the urban railway environment is specific. For the geometric position of the track, company internal standards are applied that vary from one city to another. [16] Often, insufficient professional attention is given to the condition

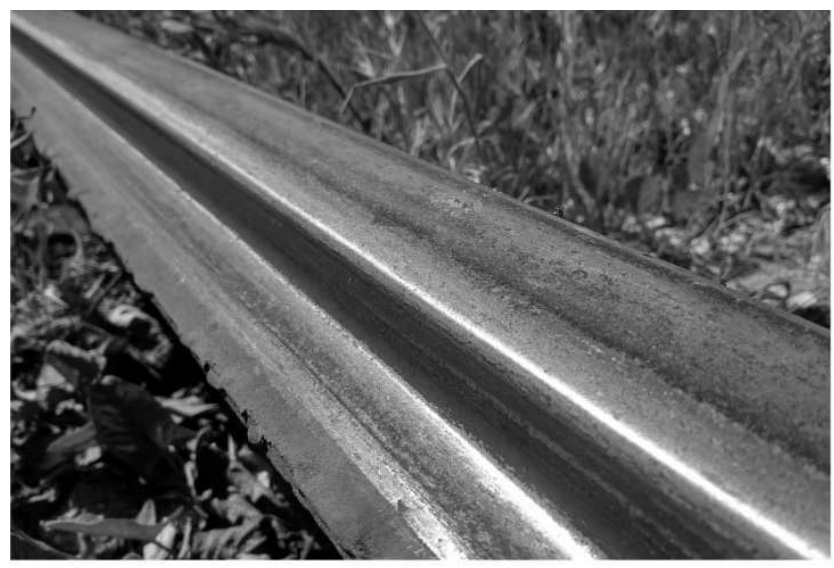

a) of the track. There is often a lack of funding for maintenance as well. Rail defects therefore have the potential to develop into larger extent than in the classical railway environment.

One of the specifics of urban railways is the occurrence of extremely small radius arches reaching 18 meters. [19] In combination with rigid wheelset guidance in the longitudinal direction, in the wheel-rail contact it comes to rise in angle of attack, high lateral and longitudinal creep, which is followed by a typical squeak sound, increased vehicle running resistance and abrassive wear in the wheel-rail contact. $[4,5,15]$ The result is an increase in the track gauge, which can reach even tens of $\mathrm{mm}$, as shown in Fig. 1 a).

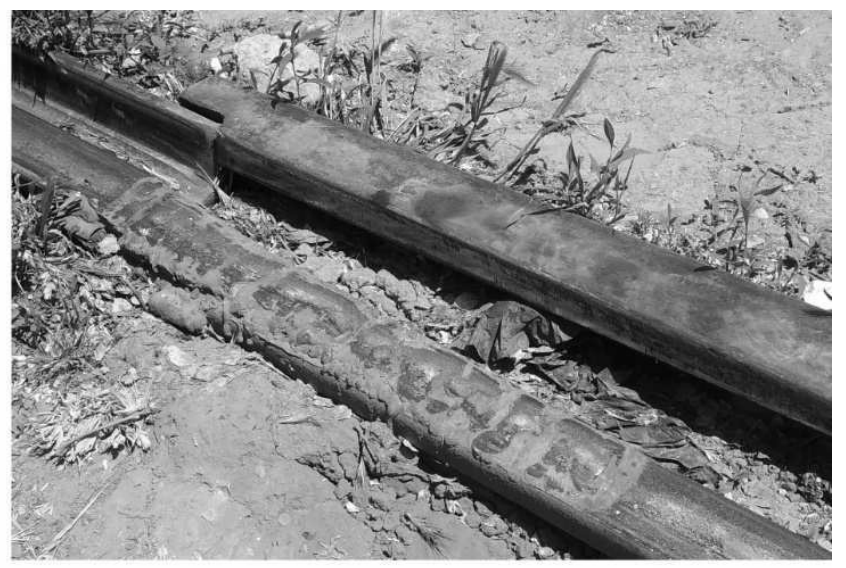

b)

Fig. 1 Track defects in operation a) Gauge extension in track arc, b) Incorrect joint 
As the vehicle passes through the arc in the jammed position, the magnitude of the angles of attack and leading forces also increases. Another typical defect are irregularities in rail belts joints, as well as rail welds. There are two commonly occuring problems in praxis. First problem is when a joint with either both or more often with only one of the ends of the rail is dropped in vertical or deflected in the lateral direction. This defect is often compensated by welding of material to one of the ends of the rail belt. The described situation in the track is documented in Fig. 1 b).

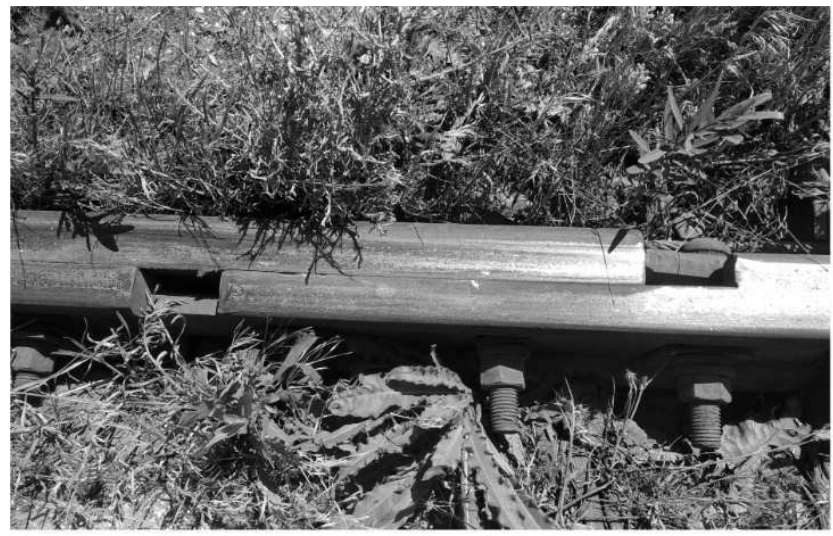

a)
The second problem is an extensive gap in the rail joint, or more precisely in the place of dilation due to maintenance neglect, as shown in Fig. 2 a). In operation it is possible to observe the efforts to remove it by cutting out a part of the rail and adding a new part of length about 30 - $40 \mathrm{~cm}$. Such a place is basically an accentuated irregularity that causes additional excitation of the vehicle's vibrations. The situation is often worsened by offset of rail joints, a situation where the right and left rail do not lie in the common plane of the cross section of the track. Such situation is captured in Fig. 2 b).

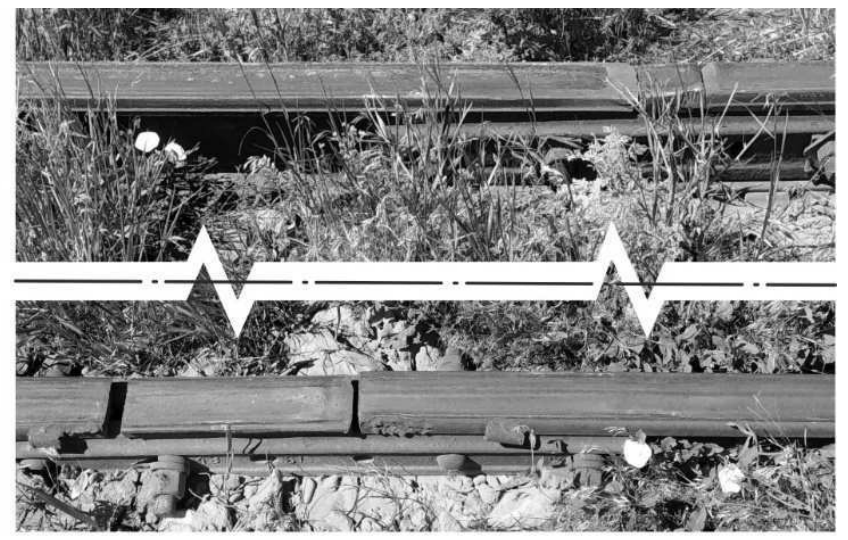

b)

Fig. 2 Rail defects in operation a) Excessive dilatation gap, b) offset of joints

Another significant particularity of urban railways is the presence of exceptionally large twisting of the track, or its buckling. This does not only apply to the twists created intentionally on the entrance to the arc, but especially to those, the cause of which is the deformation of the track foundation. The size of the permissible twist is defined by the relevant standard, for example, for a $1000 \mathrm{~mm}$ gauge track, [3] allows a maximum twisting value of 1: 250 on a track length of $6 \mathrm{~m}$. However, as this standard is not binding for urban railways, the practical situation in this context is documented in Fig. 3

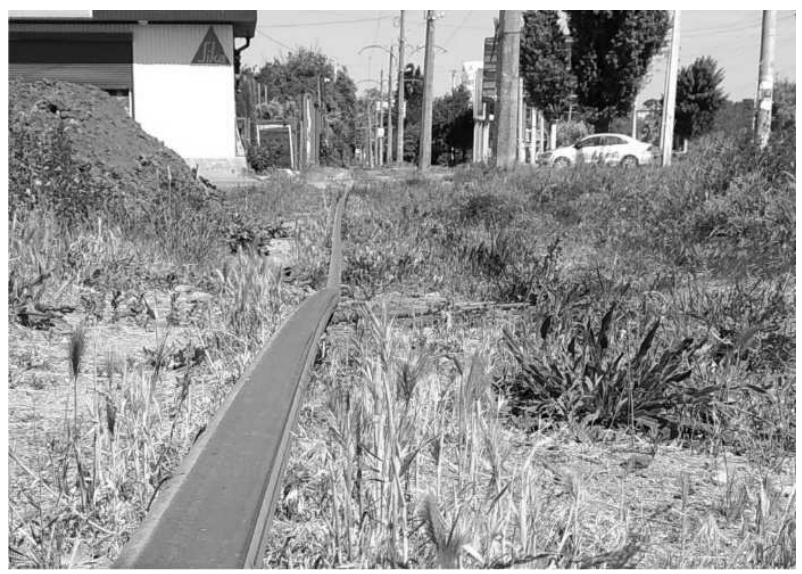

Fig. 3 Actual condition of the geometrical position of a track in terms of buckling occurrence

Driving the conventional vehicle on an uneven track is directly bound with change in the load of individual wheels $\Delta Q$ due to the stiffness of the bogie frame and the suspension activity resulting from its hyperstatic mounting. The eveness of the vertical wheel force distribution has a significant impact on vehicle safety against derailment, which is given by the ratio of the steering and vertical wheel force. The magnitude of the change in the conventional bogie, or a two-axle vehicle can be roughly determined on the basis of the moment equilibrium of the wheelsets [13]. The situation is schematically illustrated in Fig. 4th

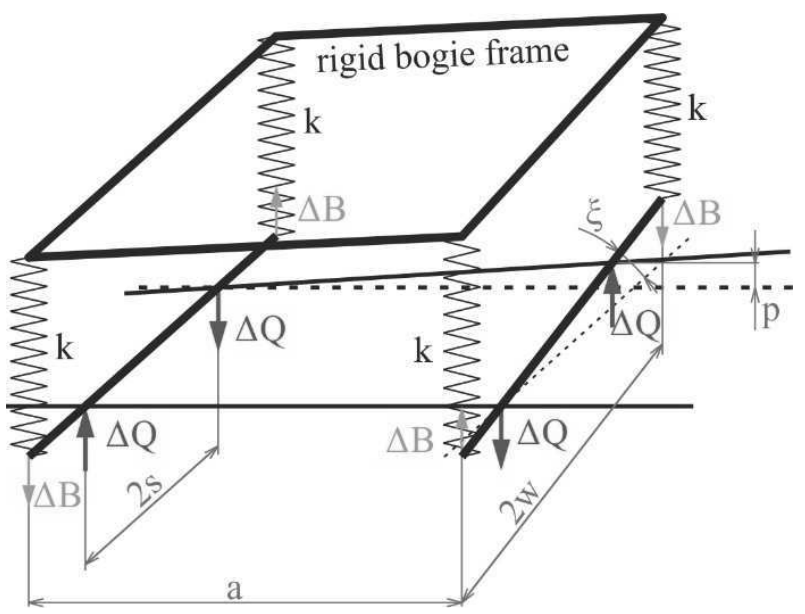

Fig. 4 Two-axle vehicle (bogie) on a twisted track

Due to the position of the vehicle on the twisted track the wheelset axis are not parallel, but they form the angle $\xi$ :

$$
\xi=\frac{p}{2 s}[\mathrm{rad}]
$$


where [rad] - the axis of the wheelset; 2s [m] - distance of the contact circles; $p[\mathrm{~m}]$ - the value of rise of one of the wheels above the level of the plane translated by the other three contact surfaces.

The fictional cross beams of the torsionally rigid frame remain parallel even when the vehicle is on a twisted track. Thus, the frame is rotated with respect to the longitudinal axis by a half angle. This is due to the fact that when the frame is rotated, the springs are deformed in such way that the change in their load does not lead to changes in vertical axle forces. Changes in the vertical load of the wheels $\Delta Q$ are thus dependent on the magnitude of changes in the load of the springs, which are dependent on their deformation $\Delta z$, for which:

$$
\Delta z=\frac{\xi}{2} \cdot w=\frac{p}{4} \cdot \frac{2 w}{2 s}[\mathrm{~m}]
$$

where $w[\mathrm{~m}]$ - distance of the spring axis from the longitudinal axis of the vehicle. Changes in the load on the springs $\Delta B[\mathrm{~N}]$ can be expressed in the form:

$$
\Delta B=k \cdot \Delta z=k \cdot \frac{p}{4} \cdot \frac{2 w}{2 s}[\mathrm{~N}]
$$

where $k\left[\mathrm{~N} . \mathrm{m}^{-1}\right]$ - spring stiffness. From the moment equilibrium of the wheelsets, the change in vertical load of the wheels $\Delta Q$ is derived:

$$
\Delta Q=\Delta B \cdot \frac{2 w}{2 s}=k \frac{p}{4} \cdot\left(\frac{2 w}{2 s}\right)^{2}[\mathrm{~N}]
$$

The safety of the vehicle against derailment is given by:

$$
\frac{Y}{Q}[-]
$$

where $Y[\mathrm{~N}]$ - guiding force, $Q[\mathrm{~N}]$ - vertical wheel force. From these relations, it is obvious that ride of a vehicle with a conventionally designed frame over buckled track poses a certain security risk. Additionally, it comes to overloading some of the rail-wheel contacts.

\section{Proposed solution}

The increase in vertical wheel forces arising as a result of ride over joints and twisted track contributes significantly to increase the effects of the vehicle on the track and to worsen the track condition. The creation and subsequent development of track defects should therefore first be understood as a consequence of an inappropriate bogie concept of the operating vehicles - not as of a poor track construction quality. Based on the dynamic analysis of current vehicles in operation, the following observations have been made to the concept of the proposed bogie:

- In case of rail vehicles operated on urban railways, it is necessary to design a bogie concept, whose ride on a twisted track does not cause any or only minimal change of vertical wheel forces $[1,2]$. The bogie should therefore be able to reach a position without suspension deformation on an uneven rail. This will allow efficient use of the effective compression of the suspension for its dynamic deflection. This requirement is fulfilled in the case of the proposed bogie design by the fact that the frame is mounted on the wheelsets by means of three bearing boxes, which ensures its "static" position on an uneven rail. This solution has been the subject of patent applications [6, 17].

- We consider the mechanism for adjusting the radial position of the wheelsets as an essential part of the bogie. As this mechanism is to be used in the urban railway environment, its correct work is required over a wide range of arc radiuses. For example, for a vehicle with a pivot distance of $6.4 \mathrm{~m}$ and a bogie wheelbase of $1.9 \mathrm{~m}$, it is necessary to ensure that the steering angle of the wheelsets is at least 3 degrees. It is desirable to perform this rotation mechanically, depending on the bogie frame angle of rotation relative to the vehicle car body.

- Ride through small radius arcs can be made much easier by using an additional tread on the outside of the wheels, with a smaller radius than the radius of the wheel tread. However, this solution requires a partial change of the strongly curved sections of the track. Descriptions of this solution are described in contributions [10 - 12, $18]$ and patent applications $[8,9]$.

- Another measure to reduce the negative impact of the vehicle on the track is a fully suspended drive. The traction motors can be mounted together with the brake discs on the bogie frame, behind the axle ends. Thus, with respect to the track, they will represent a mass suspended by the primary suspension. Engine torque can be transferred to wheelsets, for example, by means of rod couplings. This will ensure a full-featured suspension function as well as a wheelset steering mechanism.

\section{Conceptual design of the bogie}

For the bogie concept, it is necessary to know the parameters of the vehicle for which it is to be used. In our case, we came out from the parameters of the T3 tramline in the version designed for a $1000 \mathrm{~mm}$ track gauge. The pivot distance is $6.4 \mathrm{~m}$, the bogie wheelbase is $1.9 \mathrm{~m}$, the empty cab weight is $15.5 \mathrm{t}$, the effective weight of the vehicle is $9.3 \mathrm{t}$. The bogie to cab mounting location has been deliberately lowered so as not to cause any signifficant changes in wheel force [7] when the draw and braking forces come into action. The bogie concept is shown in Fig. 5 and 6. 


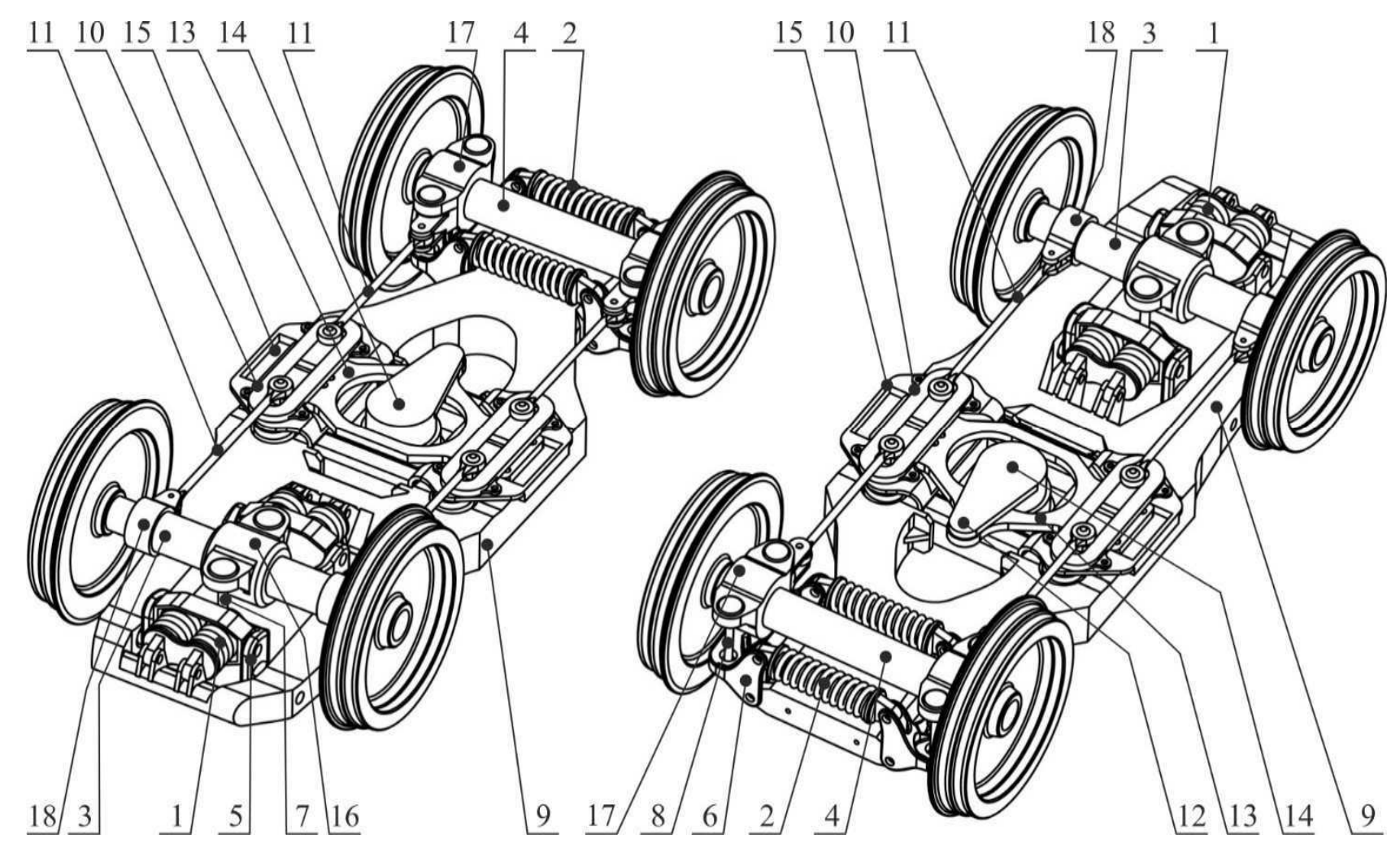

Fig. 5 The proposed bogie design - overall view

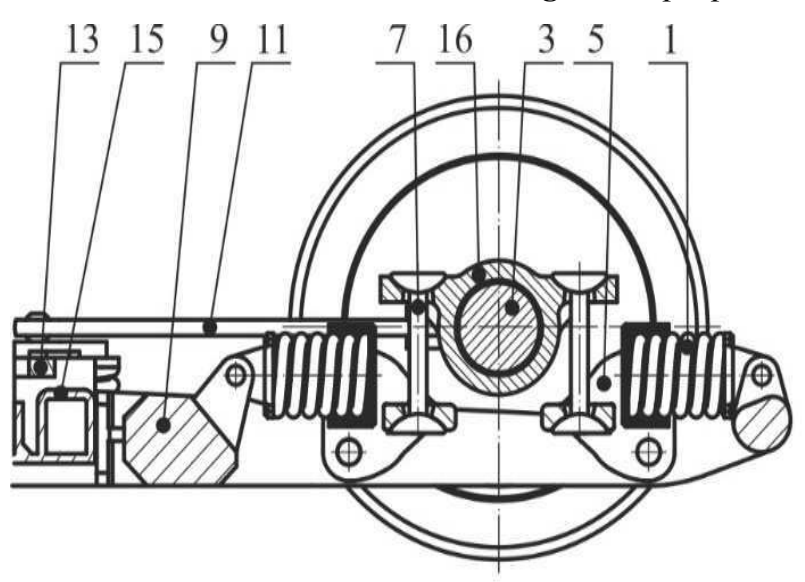

a)

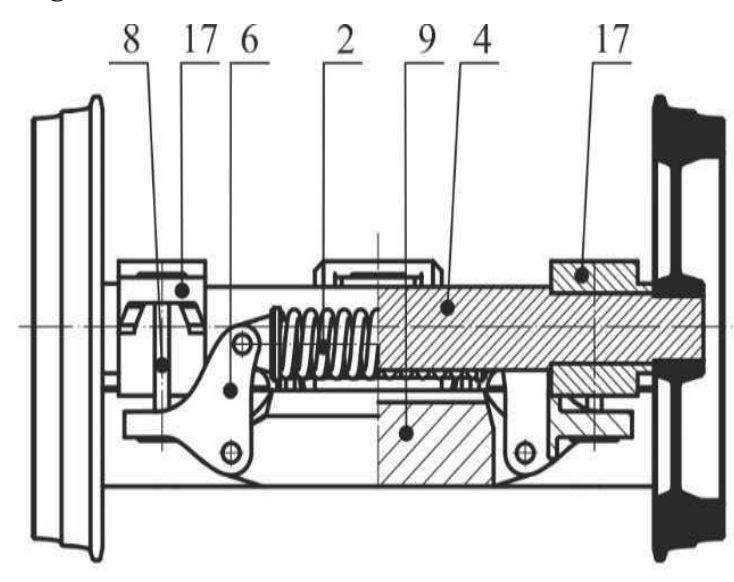

b)

Fig. 6 Design of the bogie design a) Cross-section at the point of attachment of the wheelset with one bearing housing, b) Cross-section at the point of attachment of the wheelset with two bearing boxes

\section{Design of the suspension}

Coming out from the permitted height of the coupler axis above the track, a compression of the suspension under a fully occupied vehicle of $46.5 \mathrm{~mm}$ was determined. Subsequently, a calculation of the dimensions of the individual spings of the primary and secondary suspension was performed. In order to be able to place the floor of the vehicle as low as possible, it was necessary to minimize the installed height of the primary suspension springs (1) (2) while eliminating the influence of their transverse stiffness on the wheelset steering (3), (4). Minimizing the installed height of the springs has been achieved by adding a swing element (5), (6) allowing to rotate these springs to horizontal plane, similar to the
M262 motor railcar bogie. We propose to minimize the resistance of the suspenson to setting the wheelsets to radial position by means of vertically oriented coupling rods (7), (8) at both ends with ball joints. The suspension of a wheelset (4) with two bearing boxes is specifically designed. A rocking effect of the left and right side has been achieved, which is expected to further reduce the force effects of the vehicle on the track, particularly when the rail joints are offset reciprocally as shown in fig. $2 \mathrm{~b}$ ). The vertical load is therefore transferred from the vehicle car through the guide and the pivot pin (14) to the cross member (15), which includes the mechanism for steering the wheelsets (10), further through the secondary suspension onto the bogie frame (9). The bogie frame transfers this load by means of eyes and pins to the elements of the 
primary suspension, which are the springs (1), (2), the swinging elements (5), (6) and the coupling rods (7), (8) mounted using ball joints to the swinging elements (5), (6) on one end, on the other to the bearing housing, through which also the transversal suspension is realized. In the calculation of the stiffness and consequently the dimensions of the individual springs, we derived from relations for the selection of the ratio of stiffness ${ }^{\gamma}$ of the primary and secondary suspension $k_{c 1}$ and $k_{c 2}$ for an empty (6) and loaded vehicle (7):

$$
\begin{gathered}
\gamma_{p}=2+\frac{2 \cdot m_{p}}{m_{s}}=2,200[-] \\
\gamma_{l}=2+\frac{2 \cdot m_{p}}{m_{s}+m_{u}}=2,124[-]
\end{gathered}
$$

where $m_{p}[\mathrm{~kg}]$ - estimated bogie mass, $m_{s}[\mathrm{~kg}]$ - car weight, $m_{u}[\mathrm{~kg}]$ effective weight. Based on relations (6) and (7) the ratio of stiffness of primary and secondary suspension of 2.162 was chosen. It represents also a more stiff primary and a lesser stiff secondary suspension. The total required stiffness of the vehicle suspension $k_{c}$, determined on the basis of the effective compression, is 46.5 $\mathrm{mm}$, same as in the case of the T3 tramway bogie:

$$
k_{c}=\frac{m_{u} \cdot g}{z_{u}}=1962000\left[\mathrm{~N} \cdot \mathrm{m}^{-1}\right]
$$

If the overall stiffness of the vehicle suspension is approached as a stiffness of two serially ranged suspensions, the following relationship can be applied:

$$
k_{c}=\frac{k_{c 1} \cdot k_{c 2}}{k_{c 1}+k_{c 2}}\left[\mathrm{~N} \cdot \mathrm{m}^{-1}\right]
$$

Consequently, it is possible to determine the stiffness of the secondary suspension:

$$
k_{c 2}=\frac{(1+\gamma) \cdot k_{c}}{\gamma}=2869493\left[\mathrm{~N} \cdot \mathrm{m}^{-1}\right]
$$

And the stiffness of the primary suspension:

$$
k_{c 1}=\gamma \cdot k_{c 2}=6203844\left[\mathrm{~N} \cdot \mathrm{m}^{-1}\right]
$$

Due to the limited space determined for the primary suspension, we suggest to place its springs in a horizontal plane, with the load being transmitted to them through lever elements (5) and (6). In order to minimize the resistance of the suspension on the wheelset steering mechanism in the arc, we consider necessary to include couling bars (7) and (8) in the suspension system to transfer the load from the lever element to the bearing box by means of ball joints.

In the primary suspension of the bogie we decided to use 8 springs. Four of these are used for suspension of a wheelset (3) with a single bearing box. The transverse orientation of the wheelset springs (4) with two bearing boxes enabled two pairs of the springs to be merged into one. The advantage of this solution is that a rocking effect is achieved, mitigating the effects of the vehicle on the track when passing through offseted rail joints as shown in Fig. 2b). From a spatial point of view it was necessary to reduce the diameter of these springs (2). This was enabled by the lever element (6) with a changed gear ratio to 1.416 , thereby reducing the stiffness and increasing the travel of the springs (2).

\section{Design of wheelset guidance}

The wheelset guidance function in the longitudinal direction is overtaken by the longitudinal coupling rods (11) of the wheelset steering mechanism. This mechanism is therefore continuously used to transmit the longitudinal forces between the wheelsets and the vehicle car body. The function of adjusting the radial position of the wheelsets (3), (4) is actuated by a pin (12) mounted in a flexible casing which is connected to the longitudinal axis of the bottom of a car body and to the transverse sliding gate of the mechanism (13) in the longitudinal direction, to achieve the desired wheelset rotation.

During ride of the vehicle in an arc, the bogie rotates with respect to the car body by an angle:

$$
\beta=\arcsin \frac{B}{2(R-v)}[\mathrm{rad}]
$$

Where $B[\mathrm{~m}]$ - distance of the pivot pins of the bogie, $R[\mathrm{~m}]$ radius of track arc, $v[\mathrm{~m}]$ transverse deviation of bogie from track axis given by:

$$
v=R-\left[R^{2}-\left(\frac{b}{2}\right)^{2}\right][\mathrm{m}]
$$

Thus, the wheelset steering mechanism is required to rotate the wheelsets with respect to the bogie frame by an angle:

$$
\alpha=\arcsin \frac{b}{2 R}[\mathrm{rad}]
$$

Where $b[\mathrm{~m}]$ - bogie wheelbase. This is achieved mostly by a longitudinal displacement of the bearing boxes (17) and the wheelsset guide bearing boxes (18) by the value:

$$
x_{d}=d \cdot \sin \alpha[\mathrm{m}]
$$

Where $d[\mathrm{~m}]$ - the distance between the attachment of the coupling bars (11) and the longitudinal axis of the bogie. To ensure the correct rotation of the wheelsets, it is necessary to determine the angle of the guiding groove of the mechanism gate $\delta[\mathrm{rad}]$ as well as the distance $e[\mathrm{~m}]$ of the steering mechanism gate pin (12) from the pivot pin (14). These dimensions are determinded by relation:

$$
e=\frac{x_{d} \cdot \sin \beta}{\tan \delta}[\mathrm{m}]
$$

In case of the proposed bogie design, we chose the distance e $[\mathrm{m}]$ of the steering mechanism gate pin (12) from the pivot pin (14) of $285 \mathrm{~mm}$ and the corresponding angle of the guiding groove of the mechanism gate (13) of 20 degrees. 


\section{Next steps in bogie design}

Driving mechanism and a braking system will be added to the bogie design, both fully suspended. After completing the geometric model, the simulation model will be created to evaluate the vehicle's predicted characteristics in terms of ride dynamics as well as to determine the load on the individual nodes of the structure. Consequently, strength analysis and specification of the dimensions of individual components can be made $[14,20]$.

\section{Colculsion}

A bogie concept for the urban railway environment has been proposed, which foresees a significant reduction in the negative impact on the track. Its innovative design, featuring a mounting of the frame on wheelsets using three bearing boxes, allows it to achieve a static position in the track, practically eliminating the changes in vertical wheel load forces arising from the ride on uneven tracks. This is a unique solution that is the subject of several patents. The team of authors is currently working to test the features and benefits of this solution by simulating ride dynamics of a vehicle with such bogie. On the basis of the first results, it is foreseen that the life of the track will increase several times, the energy consumption of vehicles will be reduced as well as the environmental load through the transport system.

\section{Acknowledgement}

This work was supported by the Cultural and Educational Grant Agency of the Ministry of Education of the Slovak Republic in project No. VEGA No. 1/0558/18: Research of the interaction of a braked railway wheelset and track in simulated operational conditions of a vehicle running in a track on the test stand.

\section{References}

[1] DIŽO, J., BLATNICKÝ, M. (2017). Use of multibody system dynamics as a tool for rail vehicle behaviour diagnostics. In: Diagnostyka, Vol. 17, Iss. 2, 2016, Pages 9-16, ISSN: 16416414.

[2] DIŽO, J., STEIŠUNAS, S., BLATNICKÝ, M. (2017) Vibration Analysis of a Coach with the Wheel-flat Due to Suspension Parameters Changes. Procedia Engineering, Vol. 192, 2017, pp. 107-112, ISSN: 18777058.

[3] ĎURKOVSKÝ, M., KUBALA, M. (2007). Geometric position and track layout of lines with 1000 mm gauge. (In Slovak) TNŽ 73 6361. ŽSR, Bratislava 2007.

[4] GERLICI, J., GORBUNOV, M., KRAVCHENKO, K., DOMIN, R., KOVTANETS, M., LACK, T. (2017). Slipping and skidding occurrence probability decreasing by means of the friction controlling in the Wheel-Bra- king Pad and wheel-rail contacts. In: Manufacturing Technology 17(2), pp. 179-186. 2017. ISSN: 12132489.

[5] GERLICI, J., GORBUNOV, M., KRAVCHENKO, K., PROSVIROVA, O., LACK, T. (2017). The innovative design of rolling stock brake elements. Communications - Scientific Letters of the University of Zilina 19(2), pp. 23-28. 2017. ISSN: 2261236X.

[6] GERLICI, J., LACK, T., HAUSER, V., LOULOVÁ, M., NOZHENKO, O. S., KRAVCHENKO, K. O. (2017). Carriage boogie - utility model UA 114040 U (In Ukrainian), Kyjev: Ukrainian Institute of Industrial Property, 2017. 9 p.

[7] GORBUNOV, M., PISTEK, V. KOVTANETS, M., NOZHENKO, O., KARA, S., KUCERA, P. (2017). Research to improve traction and dynamic quality of locomotives. In Vibroengineering Procedia, Vol. 13, pp. 159-164. 27th International Conference on Vibroengineering; Katowice; Poland; 26 -28 September 2017. ISSN: 2345-0533.

[8] HAUSER, V., GERLICI, J., GORBUNOV, M. I., LACK, T., KRAVCHENKO, K. O., LOULOVÁ, M., NOZHENKO, O. S., KRAVCHENKO, O. P., NOZHENKO, V. S. (2017). Curved track section - patent application no. a 201708423 (In Ukrainian) Kyjev: Ukrainian Institute of Industrial Property, 2017. $11 \mathrm{p}$.

[9] HAUSER, V., GERLICI, J., LACK, T., LOULOVÁ, M., NOZHENKO, O. S., KRAVCHENKO, K. O., PROSVIROVA, O. V. (2017). Railway vheelset and curved track section - patent application no. a201701589 (In Ukrainian). Kyjev: Ukrainian Institute of Industrial Property, 2017. $11 \mathrm{p}$.

[10] HAUSER, V., NOZHENKO, O. S., KRAVCHENKO, K. O., LOULOVÁ, M., GERLICI, J., LACK, T. (2017). Impact of wheelset steering and wheel profile geometry to the vehicle behavior when passing curved track. Manufacturing Technology. Vol. 17, Iss. 3, 2017, Pages 306-312, ISSN: 1213-2489.

[11] HAUSER, V., NOZHENKO, O. S., KRAVCHENKO, K. O., LOULOVÁ, M., GERLICI, J., LACK, T.: Innovative wheel tread design aimed to tramcar-track interaction improvement when passing curves of a small radius. 11s. 22nd Slovak-Polish Scientific Conference on Machine Modelling and Simulation, 2018. ISSN (online) 2261-236X, $11 \mathrm{~s}$.

[12] HAUSER, V., NOZHENKO, O. S., KRAVCHENKO, K. O., LOULOVÁ, M., GERLICI, J., LACK, T. (2017) Proposal of a me- 
chanism for setting bogie wheelsets to radial position while riding along track. Manufacturing Technology. Vol. 17, Iss. 2, 2017, Pages 186-192, ISSN: 12132489.

[13] KALINČÁK, D., JANÍČEK, F., KORECZ, K., LANG, A. (2004). Rail vehicles - solved examples. (In Slovak) University of Zilina, 2004. ISBN 807100-352-3.

[14] LACK, T., GERLICI, J. (2008). Analysis of vehicles dynamic properties from: The point of view of passenger comfort. Komunikacie, Vol. 10, Iss. 3, 2008, Pages 10-18, ISSN: 13354205.

[15] LACK, T., GERLICI, J. (2014). Wheel/rail tangential contact stress evaluation by means of the modified strip method Communications - Scientific Letters of the University of Zilina, Vol. 16, Iss. 3a, 2014, pp 33-39, ISSN: 13354205.

[16] LEWIS, R., OLOFSSON, U. (2009). Wheel-rail interface handbook. 842 p. 2009. ISBN: 978-14398-0146-8.

[17] LOUlOVÁ, M., HAUSER, V., GERLICI, J., LACK, T., NOZHENKO, O. S.,
KRAVCHENKO, O. P., KRAVCHENKO, K. O. (2017). Carriage bogie - utility model UA 119104 $U$ (In Ukrainian), Kyjev: Ukrainian Institute of Industrial Property, 2017. 9 p.

[18] NOZHENKO, O., KRAVCHENKO, K., LOULOVÁ, M., HAUSER, V. (2018). Double treaded wheelset riding regime change in strongly curved track from the derailment-safety point of view. In Manufacturing Technology, Vol. 18, Iss. 2, 1 April 2018, pp 303-308. ISSN: 12132489.

[19] SMETANKA, L., ŠŤASTNIAK, P., HARUŠINEC, J. (2017). Wear research of railway wheelset profile by using computer simulation. 22nd Slovak-Polish Scientific Conference on Machine Modelling and Simulations, MMS 2017; Vol. 157, 14 March 2018, ISSN: 2261236X.

[20] ŠŤASTNIAK, P., MORAVČÍK, M., BARAN, P., SMETANKA, L. Computer aided structural analysis of newly developed railway bogie frame. MATEC Web of Conferences Vol. 157, Article number 02051 ISSN: 2261236X. 